\title{
Information management as an enabler of knowledge management maturity: A South African perspective
}

\author{
C.J. (Neels) Kruger*, Roy D. Johnson \\ Department of Informatics, University of Pretoria, Pretoria 0002, South Africa
}

\section{A R T I C L E I N F O}

\section{Article history:}

Available online $\mathrm{xxx}$

\section{Keywords:}

Information and communications

technology

Information management

Knowledge management

Knowledge management maturity

\begin{abstract}
A B S T R A C T
This paper explores the much ignored but critically important subject of the perceived relationship between information and communications technology (ICT), information management (IM) and knowledge management (KM). Defining the border between ICT, IM and KM, and especially the maturity remains a highly debatable topic. These issues could be concisely summarized as being diverse and problematic and located across the spectrum of views. Prior studies suggest that even though KM is strongly entrenched and rests on the foundation of ICT and IM, very little is reported in the literature on ICT and IM as enablers to KM. From a large urban South African University engaged in numerous collaboration programs with industry, the authors gained insight into growth of KM maturity in industry groupings over a 5-year period. The authors applied an inventory developed by Kruger and Snyman [Kruger, C. J., \& Snyman, M. M. M. (2007). A guideline for assessing the knowledge management maturity of organizations. South African Journal of Information Management, 9(3). Electronic Journal [Online]. Available www.sajim.co.za. Accessed 15 October 2007] to a set of 86 organizations distributed over nine economic sectors in South Africa. In total 434 employees were interviewed over three group levels (operational, middle and senior management). This was achieved by having 178 senior practitioners to each interview three subjects (one in each group level).

The findings confirm that on average ICT (74.20\%) and IM (62.18\%) are well institutionalised in South African industry. Most organizations are aware of the distinction between ICT and IM, agreeing that ICT (78.69\%) and IM (69.65\%) are prerequisites to, and enablers of KM. In support of the concern that maturity models are biasing institutionalization towards the technological domain, findings support the argument that endeavours in IM, directly supported by ICT, are easier to implement and/or better managed and institutionalised, than endeavours that require human intervention and/or a human component to succeed.
\end{abstract}

(C) 2009 Elsevier Ltd. All rights reserved.

\section{Introduction}

In reflecting on the concept of knowledge management (KM), Wilson (2002) argues that KM means different things to different companies and some organizations having tried KM have moved on to other things. Wilson (2002) is of the opinion that even though consultation companies claim that organizations are attracted to KM, studies conducted by Bain and Company (2001) indicated that only about $35 \%$ of their world-wide sample of 451 companies were using $\mathrm{KM}$, and these companies reported a satisfaction rating of about 3.5 on a five-point scale. According to Wilson (2002), this puts $\mathrm{KM}$ in 19th position, out of 25 management tools. This compares to about $70 \%$ of organizations using benchmarking, and almost $80 \%$

\footnotetext{
* Corresponding author. Tel.: +27 12 4205322; fax: +27 123625287.

E-mail addresses: neels.kruger@up.ac.za (C.J. (Neels) Kruger), roy@up.ac.za (R.D. Johnson).
}

using strategic planning. Wilson (2002) therefore concludes that the reality of the analysis of KM is that it is a management fad, promulgated mainly by consultancy companies. However, Wilson's argument is strongly rooted in the concept that KM rests on two foundations: (1) the management of ICT and information and (2) the effective management of work practices.

Wilson's (2002) arguments, led to literature being inundated with papers focusing on either defending or refuting KM's contribution to organizational success. As an example, authors such as Kazimi, Dasgupta, and Natarajan (2004, p. 1), questioned "Why is it that a concept [knowledge management] so powerful has not delivered what it was supposed to?" while Salojarvi, Furu, and Sveiby (2005), contested that as far as studies conducted in Finnish small and medium-sized enterprises (SMEs) are concerned, there definitely is a relationship between sustainable sales growth and KM activities. Studies for most part focused on a small population or single case studies. Viewed holistically, much work remains to be done, both theoretically and empirically, before KM can be regarded 
as a perspective with explanatory power that exceeds other frameworks (Salojarvi et al., 2005).

A lot of confusion surrounding the difference between information and communication technology (ICT), information management (IM) and KM originated from the cycle of transferring data into information and information into knowledge. In rendering information making KM possible, ICT systems are often perceived as being KM systems. According to Kazimi et al. (2004) and Gallagher and Hazlett (2004) it is this reliance on technology that resulted in KM maturity models being derived from the Software Engineering Institute's Capability Maturity Model (CMM). Gallagher and Hazlett criticize KM maturity models ${ }^{1}$ arguing that they either expend too much effort in trying to address technological concerns, or are too vague and offer little in the way of practical assistance or not enough emphasis is placed upon culture and other management issues. These authors and Botha and Fouche (2002), reason that KM maturity models should not only emphasis technological concerns, but also address "softer" managerial and strategic concerns.

The reliance on "technology push" has been one of the main impediments to creating an environment conductive to knowledge sharing (Damodaran \& Olphert, 2000). According to Finestone and Snyman (2005), in an extremely diversified environment, technology often proves to be a barrier to knowledge management, especially if it is not user-friendly or tailored to the company or unit's specific needs. However, King (2005) stresses that the role technology (ICT) plays in KM should neither be ignored nor overemphasised. Ideally, the ICT infrastructure should be a platform, allowing the sharing of information as part of the KM program (Hasanali, 2002).

Defining the border between ICT, IM and KM, will in all certainty remain to be a highly debatable topic. It is the authors' belief that this debate is drawing attention away from an important factor in KM's maturity. Very little is mentioned in literature about the maturity of ICT and IM to act as enablers to KM. Beyond critique of current maturity models, the research literature has for the most part neglected to supply empirical evidence of the maturity of ICT and IM to act as enablers to KM. Similarly, seldom has the influence of CMMs' vesting of ICT and IM been reported. The aim of this paper is therefore to add to the body of knowledge in the discipline and supply KM practitioners with insight into the maturity of ICT and IM, as enablers to KM.

\section{Motivation}

The intent of this article is to move past theoretical propositions and investigate the maturity of ICT and IM, as enablers of KM by addressing the following research questions:

\section{Is ICT and information management perceived by industry to act} as enablers to knowledge management?

2. What is industries ability to manage ICT and information successfully?

3. Do organizations consider ICT and information management to be knowledge management?

The order to determine if ICT and IM are perceived by industry to act as enablers to KM, it was decided to use a questionnaire, consisting of six sections and 101 personalized questions, developed by Kruger and Snyman (2007). The questionnaire appealed

\footnotetext{
1 Crosby and Philip, 1978, SEl's Capability Maturity Model (1993), KPMG's Knowledge Management Framework Assessment Exercise (KPMG, 1999), KPMG's characterization of the Knowledge Journey (Parlby, 1999a,b), and Microsoft's IT Advisor for Knowledge Management (Microsoft, 1999).
}

to the researchers primarily because it is build upon the proposition that for KM to be of value, it must progress (mature) to the point where knowledge is seen as a strategic resource and ICT and IM as enablers to KM. In this context Kruger and Snyman (2007) supports the argument made by Grey (1998) and define the difference between knowledge and IM simply as IM working with objects such as data or information whereas KM concerns the working with people.

According to Kruger and Snyman (2005), during these early stages in KM maturity, organizations should progress to a level where they are capable of knowing and managing what constitutes data and information. At the conclusion of these stages, organizations should be capable of shifting data and information by means of ICT, all in support of business operations. To illustrate this point, Ariyachandra and Frolic (2008), argued that the nature of the existing data management infrastructure plays a crucial role in the successful deployment of a Business Performance Management (BPM) initiative. They continue with Critical Success Factors (CSF) that influence BPM implementation, encourage strong IT and business alignment while other CSFs focus on effective IT infrastructure development.

\section{Management in a multicultural environment: the South African scenario}

Deep rooted political and social requirements to integrate cultures, not in a manner where one culture dominates while others become extinct over time (Prime, 1999), make the South African environment unique in many aspects. South Africa has been challenged to make the transition into the global economy while managing the vast diversity of its people (Prime, 1999). Challenged to amalgamate Western cultures with African cultures, the South African environment portrays a clairvoyant perspective on the future of all businesses. The South African environment offers continued change, diversity and even elements of silent intolerance and conflict (Finestone \& Snyman, 2005). South Africa has past political history that this paper will not discuss in detail, except for a few factors believed to directly effect KM maturity. One of these factors is the policy of affirmative action. Affirmative action has the potential of empowering one group over the sanctioning of another which influences job security and consequently leading to an unwillingness of people to share knowledge (Finestone \& Snyman, 2005).

Another barrier to KM in the South African context is the issue of language. People are reluctant to share knowledge if they cannot understand concepts or find it difficult to convey their message. Language problems in South Africa are heightened by nine ethnicities, each with its own communities, cultural languages and parlance (Prime, 1999). Communication, which is a major element of knowledge sharing and the vesting of KM maturity, is often severely hampered when having to deal with 11 official languages. Different communication styles are more prevalent in different cultures. White South Africans predominantly adhere to Western Culture preferring an explicit style of communication such as written commitments (i.e., contracts), as the main indication of trust. In contrast, Black African cultures are more implicit in their manner of communication where oral communication is preferred (King, Kruger, \& Pretorius, 2007).

Strongly linked to the previous point, is the way South African organizations are managed. According to Prime (1999), in other multicultural countries, one culture typically dominates while others co-exist. South Africa is differentiated by the influx of different cultural pressures that need to be integrated if businesses want to compete in the global economy. South Africa is unique because of its social, political and economic history. In contrast to other culturally diverse countries, South Africa aims to create a unified culture 
wherein European, African and Asian cultures must fuse (Finestone \& Snyman, 2005).

Three management styles (Eurocentric, Afrocentric and Synergistic Inspirational) therefore directly or indirectly influenced the successful institutionalization and growth in KM. The Eurocentric approach, a predominantly western value system, emphasises characteristics such as individualism and self-centeredness (Prime, 1999). Due to the impact of colonialism and apartheid, "socialization of people along identification of races and lack of trust towards the cultural alien" (Horwitz, Bowmaker-Falconer, \& Searl, 1996) the Eurocentric approach is still dominant in South Africa. Oppressive policies of the past instilled a lack of trust in all that is alien or foreign. Previous disadvantaged groups still consider Eurocentrism as an extension of oppression, arguing that Eurocentrism lead to a socialization of people along race and ethic lines. A major portion of the South African society and business strongly resent any form of Eurocentrism.

The second management approach, an Ubuntu-based system, embraces Afrocentricity, which basically, encourages the use of home base in dealing with challenges whether internal or external to the organization. Ubuntu-thinking is considered inclusivist oriented in contrast to the Eurocentric, exclusivist approach. The Ubuntu approach is characterized by a strong sense of community and belonging, supportiveness, solidarity, management being approachable and freely available information. In general, Ubuntunism is opposed to individualism and rather embraces collectivism, which emphasises the social unit (Prime, 1999).

The third approach, Synergistic Inspirational, embraces both of the previous management approaches mentioned earlier. It involves amalgamation of time honoured African management practices, principles and philosophies with Western management methods. The authors' believe that Synergistic Inspirational is the best approach for South African organizations to follow, since it incorporates inclusivism by seeking unity in diversity.

The South African environment therefore provides a clairvoyant perspective to western industry on business confronted by challenges to merge different cultures. In practice, due to the legacy left by previous oppressive policies, most South African organizations are in a transition stage somewhere between Eurocentric, Synergistic Inspirational and Afrocentric management styles. Due to policies such as redistribution of wealth, affirmative action and black economic empowerment, government departments, service industries, Consumer goods, and basic resources such as construction, building materials and mining are more lenient towards the Afrocentric and Synergistic Inspirational management style. This is primarily due to a large percentage of these institutions senior managers these days being representative of previously disadvantaged population groups. In contrast financial institutions, education, pharmaceuticals, ICT and the automotive industry, organizations for the most part still under the control of western institutions who's management structures are still dominated by White males, predominantly support the Eurocentric management style (Thomas \& Bendixen, 2000).

\section{Methodology and data collection}

The line of reasoning followed in this article is based upon the theory that knowledge is the most strategically significant resource of the firm, and that KM is supported by ICT and IM. To understand the enabling role ICT and IM play in the success of $\mathrm{KM}$, a review of literature was conducted to assess if there are grounds for the hypothesis that ICT and IM are prerequisites to KM. In order to expand the research beyond purely theoretical and/or academic value, the decision was taken to empirically test and report on the maturity of ICT and IM as enablers to KM in South Africa.
Due to restrictions such as sensitivity, confidentiality and availability of information, preliminary research attempts showed an unwillingness of organizations to participate in the intended research. This problem was overcome by incorporating a research component into the curriculum of Master of Business Administration (MBA), Master of Information Technology (MIT) and Master of Commerce (MCom) students of a large urban university in South Africa. Since most of these students were active practitioners (97\%), and considered "senior" with regard to academic achievement as well as work experience, they became suitable surrogates to participate in the research project. [The University requires that all research studies that involve human or animal subjects must have prior approval by an Ethics Committee.]

After numerous lectures and discussions dealing with data, information, knowledge, and KM, senior practitioners used the Knowledge Management Maturity Assessment Questionnaire (KMMAQ) by Kruger and Snyman (2007) to critically evaluate the KM maturity of their own organization or with one that they were deeply familiar. Due to a number of restrictions and ethical concerns raised, only volunteering practitioners and organizations were allowed to participate in the study. In total 178 senior practitioners from nine industry groupings participated in the research the questionnaire to three organizational levels (strategic, middle/management and operational) in their respective organizations.

The decision regarding the selection of organizational groupings were guided by organizational sectors as prescribed by the Johannesburg Stock Exchange (JSE) and guidelines provided by McGregor Business and Financial Analysis (BFA). BFA supplies real-time and historical fundamental information on South African listed companies, top unlisted companies, local and international economic data as well as international financial indicators and currency exchange data. As seen in Table 1, the selection of organizational groupings led to a fairly even distribution of the total population under investigation with Government (Gov) representing the highest population (18.43\%), and Automotive and Transport (Tran) representing the smallest population (4.38\%).

The study sample consisted of interviewing 434 employees from 86 South African based organizations within the nine industry groupings. Interviews conducted among operational personnel totalled 143 (32.95\%), middle management 158 (36.41\%) and senior management 133 (30.65\%). The sample chosen was therefore not only representative of the managerial levels present in organizations, but due to the diversity of organizations participating in the study, the sample population also consisted of individuals from diverse backgrounds and cultures.

Data collected by means of the structured KMMAQ was thereafter meticulously transferred to a rating system. All data captured was digitalized through keyboard entry. In order to ensure a clean and error-free data set, the process of data capture was closely

Table 1

Industry grouping.

\begin{tabular}{llcc}
\hline Type & Abbreviation & Sample & Percentage \\
\hline Automobiles/transport & Trans & 19 & $4.38 \%$ \\
Banks and insurance & Fin & 44 & $10.14 \%$ \\
Chemicals, pharmaceuticals & Chem & 29 & $6.68 \%$ \\
Construction, building & Build & 27 & $6.22 \%$ \\
$\quad$ materials to mining & & & \\
Consulting, auditing, to & Service & 56 & $12.90 \%$ \\
$\quad$ service delivery & & & \\
Consumer goods to utilities & Goods & 58 & $13.36 \%$ \\
Education & Edu & 47 & $10.83 \%$ \\
Government & Gov & 80 & $18.43 \%$ \\
IT to telecommunications & ICT & 74 & $17.05 \%$ \\
Total & & 434 & $99.99 \%$ \\
\hline
\end{tabular}


monitored to ensure as few data entry errors as possible. Data were checked for capturing errors via standard validation checks as applied by the University Data Centre. Checks included frequencies, maximum, minimum, range and checks for missing values. After the verification process had been completed, all data collected were carefully prepared for tabular and graphic presentation, analysis and interpretation. The computer software used for analysis and modelling was SAS version 8.3, from the SAS Institute ${ }^{\mathrm{TM}}$ and the figure was created with Microsoft Excel 2007.

All statistical calculations were verified by the Bureau for Statistical and Survey Methodology (Statomet). Statomet is a facility that focuses on the scientific design and management of research. Statomet provides statistical advice on all aspects of research design and management, and aims to improve the quality of research by rendering a multidisciplinary service to public and private organizations. However, human understanding and interpretation, both important factors contributing to valid knowledge (Cornford \& Smithson, 2004), meant that the interpretation of results, as compared to the analysis of results, had to be done in a more subjective and "interpretive" manner.

The analysis that follows consists of the descriptive statistics used for each question. Statistics established the basic measures of the response variable for every question covering aspects pertaining to ICT and IM. Unless specifically stated, all findings are evaluated from a positive response basis (i.e., "Yes, definitely" and "Yes, but not significantly"). Where the probability of exceeding the $\operatorname{norm}(p$-value) was found to be less than 0.05 , the decision rule was to reject the null hypothesis at a $5 \%$ level of significance.

\section{Discussion, results and findings}

In order to extract comparable and meaningful findings from within the knowledge management maturity questionnaires, Kruger and Snyman (2007) utilized a four-point Likert scale to express the degree of agreement with the posed questions. This maturity rating system was designed to calculate an overall KM maturity score based on multiple sections and expressed as values or percentages. The knowledge management maturity sections were calculated as follows:

- Cover page: Demographics, q.1-4 (Max score =0).

- Section 1: ICT management, q.5-9 (Max score =20).

- Section 2: Information management, q.10-28 (Max score = 76).

- Section 3: KM issues (principles, policy, strategy), q.29-52 (Max score $=88$ ).

- Section 4: Implementation of KM, q.53-84 (Max score =94).

- Section 5: Ubiquities knowledge, q.85-103 (Max score =76).

- Section 6: Assessment of KM growth, q.104: $($ Max score =4).

The overall KM maturity was calculated by adding the scores achieved in the individual sections together $(20+76+88$ $+94+76+4$ ) for a total of 358 points.

Note: Although the questionnaire by Kruger and Snyman (2007) address the total spectrum of KM maturity, this article only focuses on the role ICT and IM play as enablers to KM. (Full details of all statistical analysis done as well as a summary of all results obtained are on request, available from the authors.) To supply a holistic perspective to the line of reasoning proposed, that ICT and IM are

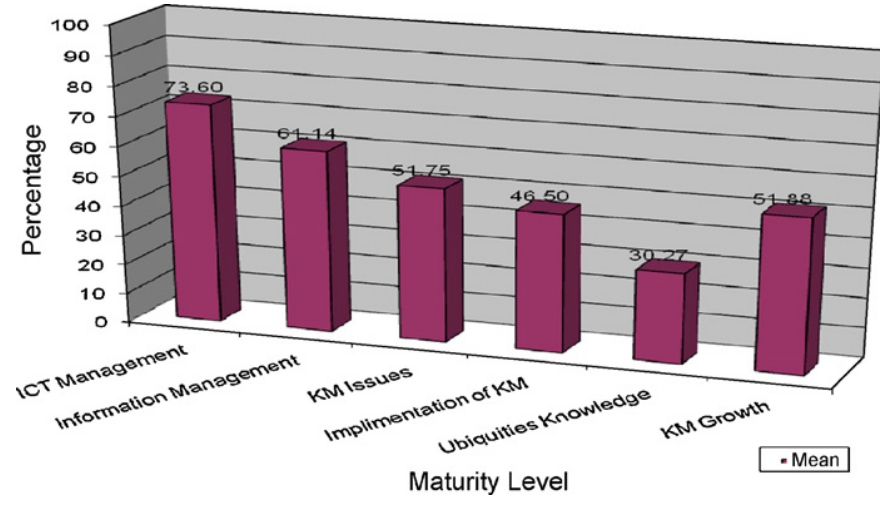

Fig. 1. Knowledge management maturity per maturity sections.

enablers to KM maturity, overall KM maturity scores achieved are next discussed in relation to ICT management and IM

\subsection{ICT management}

In total, 434 employees in 86 organizations participated in the study using a survey instrument to examine ICT management (Appendix A). The average KM maturity score obtained by all organizations totalled 175 points. This constitutes an overall maturity of $48.89 \%$ (175/358). The score obtained for ICT and information management as enablers to KM, totaled $73.60 \%$ and $61.14 \%$, respectively. With a score of $51.75 \%$, organizations are able to successfully identify KM issues, principles, policies, and strategies. However, totaling a score of only $46.50 \%$ the ability to successfully identify KM issues, principles, policies, and strategies are not carried through to successful implementation of KM. Also, in achieving a score of only $30.25 \%$, South African organizations struggle with extending KM beyond their borders (ubiquities knowledge) (Fig. 1).

With regard to growth in KM maturity, the average score obtained by South African organizations interviewed was $51.88 \%$. Slightly more than $20 \%$ (20.28\%) of interviewees indicated that their organizations experienced rapid growth (3+ maturity levels), in KM maturity, $52.12 \%$ is of the opinion that although growth occurred, it was not significant (1-2 maturity levels), and while $22.17 \%$ argued that although no growth took place there will probably be growth within the next 5 years. Slightly more than $5 \%$ (5.43\%) were of the opinion that a decline in KM growth occurred over the past 5 years.

As mentioned, the average score obtained for ICT management was $73.60 \%$. With regard to ICT being an enabler of KM (i.e., Boon, 1990; Gallagher \& Hazlett, 2004; Gurteen, 1998; Kruger \& Snyman, 2005), findings suggest a definite trend towards ICT being an enabler of KM with most industries achieving high scores in ICT management (Build $78.33 \%$, Fin $82.95 \%$, Service $76.42 \%$ and Goods $72.75 \%$ ) also achieving higher than average score in KM maturity (55.67\%, 53.29\%, 51.29\% and $49.87 \%)$. The converse is also true where industries (Chem 66.03\%, Gov 66.87\% and Edu 65.54\%) achieving lower ICT management scores achieved lower than average scores in KM maturity (Table 2, Fig. 2). Exceptions to the rule are organizations in the ICT and Automotive and Transport industries (Tran) achieving high scores in the ability to manage ICT, and moderate scores regarding the level of KM maturity.

Table 2

ICT Mgnt., Info. Mgnt. and KM maturity by industry grouping.

\begin{tabular}{|c|c|c|c|c|c|c|c|c|c|c|}
\hline & Trans & Fin & Chem & Build & Service & Goods & Edu & Gov & ICT & Avg. \\
\hline ICT management & 78.42 & 82.95 & 66.03 & 78.33 & 76.42 & 72.75 & 65.54 & 66.87 & 78.85 & 74.02 \\
\hline Information management & 59.76 & 68.95 & 65.29 & 71.49 & 61.86 & 61.77 & 52.29 & 55.24 & 62.98 & 62.18 \\
\hline KM maturity & 49.58 & 53.29 & 46.92 & 55.67 & 51.29 & 49.87 & 42.52 & 46.40 & 49.06 & 49.40 \\
\hline
\end{tabular}






Fig. 2. ICT Mgnt., Info. Mgnt. and KM maturity by industry grouping.

These findings indicated that when viewed holistically, South African industry is reaching the preliminary level of aptitude needed to successfully institutionalize KM endeavours (Appendix A).

Questionnaire responses revealed that most interviewees held positive attitudes regarding the capability of their organization to evaluate (q.5, 91.44\%), Design (q.6, 81.21\%) and Plan (q.7, 90.26\%) an ICT system. The vast majority of those interviewed were also positive (q.8, 82.68\%) regarding the effectiveness of their organization's ICT infrastructure.

Though most respondents agreed with the statement that ICT is an enabler of $\mathrm{KM}$ (q.9, 78.69\%), an alarming number of respondents are still under the impression that ICT is KM (q.9, 21.31\%).

\subsection{Information management}

The same 434 employees in 86 organizations participated in the study using a survey instrument to examine information management (Appendix B). The average score obtained for this maturity section (Table 2) was 46.47 out of 76 (61.14\%). With regard to IM being an enabler of KM (i.e., Ariyachandra \& Frolic, 2008; Boon, 1990; Henczel, 2000; Kruger \& Snyman, 2005; Kruger \& Snyman, 2007), findings also indicate a definite trend towards IM being an enabler of KM. Again industries achieving high scores in IM (Build 71.49\%, Fin 68.95\%, Services 61.86\% and Goods 61.77\%) also achieved higher than average score in KM maturity (55.67\%, $53.29 \%, 51.29 \%$ and $49.87 \%$ ). In contrast, industries such as Government (55.24\%) and Education (52.29\%) achieved lower than average scores in both ICT management and KM maturity (46.40\% and $42.52 \%$ ).

There were exceptions to the rule, with organizations in the ICT and Pharmaceutical (Chem) industries achieving moderate to high scores in IM while only achieving moderate scores for KM maturity. Viewed holistically, the findings indicate that when achievement in ICT and IM are viewed together in the context of overall KM maturity, there is a trend towards higher KM maturity scores where IM is supported by ICT and vice versa. This could account for the below average KM maturity score achieved by the Pharmaceutical (Chem) grouping (in spite of a high IM score), this argument does not hold true regarding the ICT grouping.

The majority of interviewees answered positively to those questions regarding the identification of information Needs (q.16, $81.11 \%$ ), Acquisition (q.17, 86.34\%), Storage (q.18, 84.30\%), Distribution (q.19, 78.34\%), Retrieval (q.20, 80.88\%), Protection (q.22, 77.88\%), Inventory Management Systems (q.25, 77.88\%) and Database Management (q.26, 85.25\%).
Positive responses were made to questions of whether their organization had a clearly defined information Policy (q.10,69.35\%) and Strategy (q.11, 70.97\%) in place, nearly the same number of respondents, as those that agreed that IM is a prerequisite for KM (q.28,69.65\%), responded positively (yes, definitely and yes, but not significantly).

By conducting Proc Frequency Test of Variables on questions 10 and 11 by 28 , the respondents that answered "yes" to q.10, 73.38\% also answered "yes" in q.28. Of the respondents that answered "yes" in q.28, $72.64 \%$ also answered "yes" to q.10. In a similar manner $73.42 \%$ of respondents that said "yes" to q. 11 also said "yes" to q.28 and $74.66 \%$ saying "yes" to q.28 also said "yes" to q.11 (Table 3 ).

A Chi-square Test of Independence for the Hypothesis that q.10 and q.28 are independent resulted in a p-value of $0.0127(<0.05)$. Thus the hypothesis was rejected finding that $\mathrm{q} .10$ and $\mathrm{q} .28$ are "dependent". The research hypothesis proposed that q.11 and q.28 are independent resulted in a $p$-value of $0.0084(<0.05)$. Thus the second hypothesis was rejected finding that q.11 and q.28 are "dependent" (Table 4).

This Chi-square testing establishes that there is a correlation between a clearly defined IM policy and IM strategy and the understanding of IM being a prerequisite for KM. Yet, of respondents that agreed their organizations have an information policy (q.10, $69.35 \%$ ) and an information strategy (q.11, 70.97\%) in place, half of the positive respondents (31.80\% information policy, $34.56 \%$ information strategy) were of the opinion that it is "not significantly" institutionalised.

Respondents indicated in a positive manner that they understood "which" information resources are crucial to their businesses (q.12, 88.94\%). Respondents were also clear about which managers are accountable for information resources (q.13, 80.18\%). Also, key information is easily available (q.14, 76.27\%). However, endeavours such as the training of employees to access sources of information relevant to their jobs (q.15, 65.21\%), the disposal of information (q.21, 68.20\%) and determining the value and cost of information (q.23, 59.12\%), all achieved lower scores.

Endeavours requiring human intervention and dedicated commitment to succeed, such as the training of employees to access sources of information relevant to their jobs (q.15, 65.21\%), the disposal of information (q.21,68.20\%), determining the value and cost of information (q.23,59.12\%), and the institutionalization of an information service/library (q.27, 66.82\%), scored considerably lower than endeavours such as the institutionalization of inventory management systems (q.25, 77.88\%) and Databases (q.26, $85.25 \%$ ). Of interest is that the identification of information needs also requiring human intervention, received a high score of $81.11 \%$ 
Table 3

Frequency statistics.

\begin{tabular}{|c|c|c|c|c|}
\hline & & 1 & 2 & Total \\
\hline \multicolumn{5}{|c|}{ q.10: Clearly defined IM policy by q.28. Information management is regarded as: The FREQ Procedure: Table of Q10 by Q28 } \\
\hline \multirow[t]{4}{*}{ Yes } & Frequency & 215 & 78 & 293 \\
\hline & Percent & 50.59 & 18.35 & 68.94 \\
\hline & Row Pct & 73.38 & 26.62 & \\
\hline & Col Pct & 72.64 & 60.47 & \\
\hline \multirow[t]{6}{*}{ No } & Frequency & 81 & 51 & 132 \\
\hline & Percent & 19.06 & 12.00 & 31.06 \\
\hline & Row Pct & 61.36 & 38.64 & \\
\hline & Col Pct & 27.36 & 39.53 & \\
\hline & Total & 296 & 129 & 425 \\
\hline & & 69.65 & 30.35 & 100.00 \\
\hline \multicolumn{5}{|c|}{ q.11: Clearly defined IM strategy by q.28. Information management is regarded as: The FREQ Procedure: Table of Q11 by Q28 } \\
\hline \multirow[t]{4}{*}{ Yes } & Frequency & 221 & 80 & 301 \\
\hline & Percent & 52.00 & 18082 & 70.82 \\
\hline & Row Pct & 73.42 & 26.58 & \\
\hline & Col Pct & 74.66 & 62.02 & \\
\hline \multirow[t]{6}{*}{ No } & Frequency & 75 & 49 & 132 \\
\hline & Percent & 17.65 & 11.53 & 31.06 \\
\hline & Row Pct & 60.48 & 39.52 & \\
\hline & Col Pct & 25.34 & 37.98 & \\
\hline & Total & 296 & 129 & 425 \\
\hline & & 69.65 & 30.35 & 100.00 \\
\hline
\end{tabular}

Frequency missing $=9$.

\begin{tabular}{|c|c|c|c|}
\hline Statistics & $\mathrm{DF}$ & Value & Prob. \\
\hline \multicolumn{4}{|c|}{ q.10: Clearly defined IM policy by q.28. Information management is regarded as: Statistics of Table of Q10 by Q28 } \\
\hline Chi-square & 1 & 6.2146 & 0.0127 \\
\hline Likelihood ratio Chi-square & 1 & 6.0784 & 0.0137 \\
\hline Continuity Adj. Chi-square & 1 & 5.6592 & 0.0174 \\
\hline Mantel-Haenszel Chi-square & 1 & 6.2000 & 0.0128 \\
\hline Phi coefficient & & 0.1209 & \\
\hline Contingency coefficient & & 0.1200 & \\
\hline Crammer's $V$ & & 0.1209 & \\
\hline \multicolumn{4}{|c|}{ q.11: Clearly defined IM strategy by q.28. Information management is regarded as: Statistics of Table of Q11 by Q28 } \\
\hline Chi-square & 1 & 6.9540 & 0.0084 \\
\hline Likelihood ratio Chi-square & 1 & 6.7750 & 0.0092 \\
\hline Continuity Adj. Chi-square & 1 & 6.3554 & 0.0117 \\
\hline Mantel-Haenszel Chi-square & 1 & 6.9376 & 0.0084 \\
\hline Phi coefficient & & 0.1279 & \\
\hline Contingency coefficient & & 0.1269 & \\
\hline Crammer's $V$ & & 0.1279 & \\
\hline
\end{tabular}

Effective sample size $=425$; frequency missing $=9$.

(q.16). Possibly, this is due to identification of information needs being a prerequisite to the building of databases and the institutionalization of information systems.

Analysis of the difference in the mean score of questions that test the importance of understanding the value of information resources (q.12, 88.94\%), accountability for information resources (q.13, 80.18\%), whether key information is easily available (q.14, $76.27 \%$ ), the training to access sources of information relevant to their jobs (q.15, 65.21\%), information disposal (q.21,68.20\%), determining the value and cost of information (q.23, 59.12\%) and the institutionalization of an information service/library (q.27, 66.82\%) indicated that there is a significant difference in scores between endeavours that require understanding, compared to endeavours that require active participation.

Questions 15, 21, 23 and 27, all scored considerably lower than endeavours analysed in questions $12-14$. Tests for Normality (Shapiro-Wilk Test) revealed that the data is not normal. However tests for Location (Wilcoxon Signed Rank) at a $p$ value $<0.001$ rejected the null hypothesis that Ho: Mean understanding $=$ mean participation (average for questions 12-14 compared to 15,21 , 23 and 27), and accepted that Ha: Understanding $\neq$ participation (i.e., there is statistically significant differences between the scores achieved in "Understanding" IM and "Participating" in IM) (Table 5).

Of interest is that protection of information (q.22, 77.88\%), scored considerably higher than information disposal (q.21, $68.20 \%$ ) or determining the value and cost of information (q.23, $59.12 \%)$.

\section{Knowledge management maturity by industry grouping}

Due to the structure of the questionnaire, captured data also enabled the analysis of KM maturity for different organizational types, as applicable to South African Industries. The industry sector that achieved the highest overall knowledge management maturity score was the Resources sector, with a total score of 199.33/358 or $55.67 \%$. Resource organizations not only recorded the highest growth in maturity over the past 5 years $(69.44 \%)$, but also 
Table 5

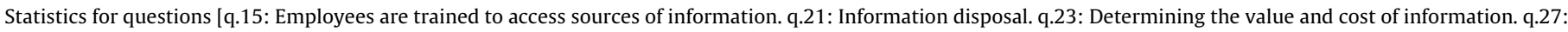

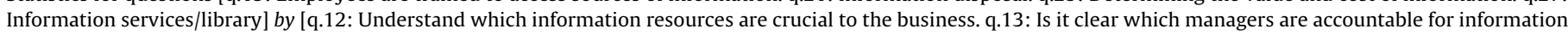
resources. q.14: Key information is easily available].

\begin{tabular}{|c|c|c|c|c|}
\hline Test & Statistics & & $p$ value & \\
\hline \multicolumn{5}{|l|}{ Tests for location: Mu0 $=0$} \\
\hline Student's & $\mathrm{t}$ & 10.85974 & $\operatorname{Pr}>[t]$ & $<0.001$ \\
\hline Sign & $\mathrm{m}$ & 82.5 & $\operatorname{Pr} \geq[\mathrm{M}]$ & $<0.001$ \\
\hline Wilcoxon signed rank & $\mathrm{s}$ & 19,277 & $\operatorname{Pr} \geq[S]$ & 0.001 \\
\hline \multicolumn{5}{|l|}{ Test for normality } \\
\hline Shapiro-Wilk & $\mathrm{W}$ & 0.982763 & $\operatorname{Pr}<W$ & $<0.001$ \\
\hline Kolomogoroc-Smirnov & $\mathrm{D}$ & 0.098784 & $\operatorname{Pr}>D$ & $<0.0100$ \\
\hline Cramer-von Mises & W-Sq & 0.68631 & $\mathrm{Pr}>\mathrm{W}-\mathrm{Sq}$ & $<0.0050$ \\
\hline Anderson-Darling & $\mathrm{A}-\mathrm{Sq}$ & 3.519697 & $\mathrm{Pr}>\mathrm{A}-\mathrm{Sq}$ & $<0.0050$ \\
\hline
\end{tabular}

achieved the highest percentages in Section 2 (Information Management, 71.49\%), Section 3 (Principles, Policy, Strategy, 61.15\%) and Section 4 (Implementation of KM) of the questionnaire. In Section 1 (ICT Management, 78.33\%) and Section 5 (Ubiquities Knowledge, $32.01 \%$ ) scores were not significantly lower than the highest scores forwarded (82.95\% ICT Management and 35.94\% Ubiquities Knowledge) by all industries. Operational, middle- and senio-management rated overall maturity in a similar manner at $52.82 \%, 57.46 \%$ and $56.23 \%$, respectively. Operational and middle managers also forwarded similar figures $75.0 \%$ and $72.50 \%$ regarding maturity growth. Senior managers rated growth in maturity considerably lower at $61.1 \%$. Of interest is that the larges score difference between the different managerial levels occurred primarily in maturity Section 3 (the formulation of KM issues, policy and strategy) where operational personnel rated the industry at $53.83 \%$ and middle and senior management forwarding scores of $64.88 \%$ and $63.51 \%$, respectively. Viewed holistically, findings indicate that Resources organizations are fairly mature regarding the management of information and ICT.

The organization type that achieved the second highest overall score was the financial sector with a total score of 190.79/358 or $53.29 \%$. In comparison to other industries, the financial industry obtained high scores in Section 2 (Information Management, 68.03\%) and Section 3 (the formulation of KM issues, policy and strategy, 57.85\%) with slightly above average scores in Section 4 (Implementation of KM, 48.18) and Section 5 (Ubiquities Knowledge, 32.08\%). The Financial sector significantly outperformed all other organizational types regarding the management of ICT (Section $1,82.95 \%$ ). An interesting finding is that the maturity growth of these organizations is perceived to be extremely moderate, achieving only a sixth place with an average score of $48.83 \%$. Even though all managerial levels forwarded similar scores regarding the management of ICT (Section 1), score differences occurred regarding the management of information (Section 2; Operational Personnel, 59.37\%; Middle Managers, 74.53\%; Senior Managers, 71.42\%), and the formulation of KM issues, policy and strategy (Section 3; Operational Personnel, 52.34\%; Middle Managers, 55.84\%; Senior Managers, 66.15\%). This strongly hint at an overestimation by managers regarding the maturity of information management and by senior managers regarding their ability to formulate KM issues, policy and strategy. This argument of overestimation of achievement is supported by the finding that operational personnel rated the implementation of KM (Section 4) at 43.61\%, considerably lower than what middle and senior management did at $52.96 \%$ and 48.63\%, respectively,

The third highest score was achieved by organizations in the Service delivery grouping with an overall score of $183.64 / 358$ or $51.22 \%$. These organizations recorded high scores in Section 3 (the formulation of KM issues, policy and strategy), and Section 4 (Implementation of KM) and moderate scores in Section 1 (ICT Management), and Section 2 (Information Management), and extremely low scores in Section 5 (Ubiquities Knowledge) of the maturity questionnaire. Maturity growth in this sector is high at $61.16 \%$. Of interest is that score difference between the different maturity sections is marginal with operational personnel, middle managers and senior managers deciding on a fairly similar overall maturity scores (Operational, 50.85\%; Middle Management, 50.54\%; Senior Management, 52.67\%). There is however a significant difference in managerial levels perception of growth in KM with operational personnel scoring growth in maturity at $65.78 \%$, middle management at $55.00 \%$ and senior management at $63.23 \%$.

Organizations within the Goods grouping received the fourth highest maturity score, obtaining an average score of 178.55/358 or $49.87 \%$. Although organizations in this sector achieved just above average to just below average scores in Sections 1-4 of the maturity questionnaire, they received the third highest score regarding knowledge management growth $(54.62 \%)$ and the second highest score in Section 5 (Ubiquities Knowledge, 34.25\%). Similar to service organizations, the score difference between the different maturity sections is marginal over most maturity sections with operational personnel, middle managers and senior managers deciding on a fairly similar overall maturity scores (Operational, 49.30\%; Middle Management, 47.90; Senior Management, 52.51\%). There is again an indication that senior managers overestimate the formulation of KM issues, policy and strategy (Section 3), with senior managers forwarding a score of $53.94 \%$, compared to scores forwarded by operational and middle managers of 47.005 and $47.13 \%$, respectively. Differences regarding managerial levels perception of growth in KM are also evident with operational personnel scoring growth in maturity at $54.16 \%$, middle management at $51.31 \%$ and senior management at $58.82 \%$.

Automobiles/transport organizations received the fifth highest score, totalling an average score of $177.52 / 358$ or $49.58 \%$. An interesting finding is that these organizations scored the lowest average score (45.33\%) in Section 3, formulation of knowledge management issues, policies and strategies. In comparison scores achieved in Section 1 (ICT Management, 78.42\%), Section 2 (Information Management) and Section 4 (Implementation of KM, 50.11\%) are moderate, with the highest score obtained in Section 5 (Ubiquitous Knowledge, 35.94\%) for all sectors covered. Review of the scores forwarded by the different managerial levels indicate that the low score achieved in maturity Section 3 (formulation of knowledge management issues, policies and strategies) is primarily due to operational managers scoring this section at $36.75 \%$, compared to scores of $48.48 \%$ and $50.00 \%$ forwarded by middle and senior managers. This difference in score is repeated in the scores forwarded by operational personnel and managers regarding the implementation of KM (Section 4) where managers allocated scores of $57.09 \%$ and $53.95 \%$, and operational personnel $38.65 \%$, respectively. This hint at an overestimation by managers regarding the formulation of KM issues, policy and strategy and an unwillingness or possibly even an inability to implement KM. This quandary is supported by the 
finding that even though maturity growth for Auto/Transport organizations is moderate at $52.63 \%$, large differences occurred between the scores forwarded by the different managerial levels with operational personnel at $33.33 \%$ not supporting the claim of middle (70.83\%) and senior management (53.57\%) that significant growth in KM occurred.

Due to the nature of their business, ICT organizations scored high in Section 1 (ICT management) of the questionnaire, achieving an average score of $78.85 \%$. Subsequent maturity levels follow a trend similar to the average maturity score achieved by all industries, become incrementally smaller as the level of maturity increases. Senior managers in ICT organizations, at $60.0 \%$, rated the overall maturity to be considerably higher than the rating attributed to middle management $(46 \%)$ and operational personnel $(43 \%)$. Of interest is that the bulk of the differences in scores between top, middle and operational personnel are vested primarily in the scores allocated to Sections 2-4 of the questionnaire, i.e., information management, formulation of knowledge management issues, policies and strategies and the implementation of knowledge management. Again, there is indication that senior management is overestimating their ability to manage information, formulate knowledge management issues, policies and strategies and implement KM. Operational personnel at $39.28 \%$ are also not supportive of the claim by middle (50.00\%) and senior management (60.52\%) that significant growth in KM occurred.

Chemical and pharmaceutical organizations achieved an overall maturity score of $168.00 / 358$ or $46.9 \%$. Apart from Section 2 (Information Management) scores achieved in all sections of the questionnaire are lower than the average score achieved per maturity section by all organizational groupings interviewed. Maturity growth over the last 5 years is $47 \%$ and is also below the average score of $51 \%$. This is only slightly better than the lowest score achieved by the worst performer (the educational industry) at $42 \%$. An interesting observation is that although senior managers in this industry scored the overall maturity at 55\%, operational personnel at $44 \%$ rated the overall maturity slightly higher than middle management did at $43 \%$. This trend is repeated in the scores forwarded by the different managerial levels regarding the growth in KM, with operational personnel forwarding a score of $50.00 \%$, middle managers forwarding a score of $40.90 \%$ and senior managers $52.77 \%$. The low score attributed to middle management is primarily due to middle managers perceiving level 3 (formulation of knowledge management issues, policies and strategies) to be inadequate.

The governmental sector achieved an overall maturity score of $166.11 / 358$ or $46.39 \%$. Government departments achieved scores over all maturity levels (except Section 5) considerably lower than the average score obtained by all participating organizations. However, an interesting finding is that growth of maturity over the past 5 years at $49 \%$ are moderate compared to other groupings. When findings are broken down to reveal the scores allocated by the different managerial levels that made up the Government departments, it was found that the difference in score between the different managerial levels within Government departments take on an extremely interesting dimension with senior and operational personnel rating growth in maturity the same at $43.75 \%$ and $42.85 \%$. This is considerably lower than the score attributed to middle managers at $57.14 \%$.

Educational institutions not only received the lowest maturity score of all groupings interviewed (152/358 or $42.45 \%$ ), but also forwarded the lowest maturity scores over nearly all maturity levels. Growth of maturity over the past 5 years was also the lowest of all organizational sectors interviewed, receiving a score of $42.02 \%$. Senior managers rated growth in KM at $44.23 \%$ and the overall maturity at $47.55 \%$, middle management rated growth in $\mathrm{KM}$ at $44.44 \%$ and overall maturity at $39.86 \%$ while operational personnel rated growth in KM at $37.5 \%$ and maturity at $41.44 \%$. The relatively low score attributed to middle management could be traced to middle managers scoring levels 2 (information management) significantly lower than any other maturity sections.

\section{Conclusion}

The South African scenario can be considered a benchmark for developing economies characterized by continued change, diversity and even elements of silent intolerance and conflict. The research results meet the demand for qualitative research in providing an understanding within the particular context of South Africa. Confusion regarding the difference between ICT, IM and $\mathrm{KM}$ is still evident within South African Industry. One fifth of the respondents $(21.31 \%)$ regard ICT as KM while less than one third of the same respondents (30.35\%) regard IM to be KM. Industries differ in ability to manage ICT and IM successfully. Construction, Building Material and Mining (Build) organizations scored high in both ICT and IM, while Government and Educational institutions scored low in ICT and IM.

Most organizations surveyed agree that ICT (78.69\%) and IM (69.65\%) are enablers to KM, supporting the position that IM, and ICT are prerequisite to KM. Findings confirm that leading KM maturity organizations have sound ICT management practices in place. Even though score differences could mainly be attributed to consistency in achievement over all maturity sections, it was noted that leaders all achieved higher than average scores particular over Section 1 (ICT Management), Section 2 (Information Management) and Section 3 (Formulation of KM issues, policy and strategy) of the questionnaire. Medium-sized organizations in both the Financial and Resources industries were typical examples in case. However, even with strong ICT support and having sufficient KM policies and strategies in place, insufficient information management was also found to negatively impact on the overall ability to institutionalise KM successfully. On average organizations that did not fare well achieved below average scores over maturity Sections 1-3 of the KM maturity questionnaire. The dramatic decline in KM maturity in the latter stages of large financial organizations' scores, primarily due to insufficient information management, proved to be a definite point in case.

Insufficient and/or immature ICT and information management lead to problems with regard to supporting KM endeavours beyond organizational borders. Findings indicated that even though Services organizations know how to formulate and implement KM issues, policies and strategies successfully, they struggle with coming to grips with managing knowledge situated outside the borders of their organizations. Similarly, the below average performance in ICT management (66\% compared to an average score of $73 \%$ ), achieved in the Pharmaceutical organizations filtering through to successive maturity levels. This again strongly hints at the enabling role of ICT being insufficient. The relatively low score achieved in the Educational industry, primarily due to middle managers perceiving information management to be inadequate, strengthening the argument that information management, similar to ICT is a prerequisite to successful institutionalization of knowledge management.

In investigating diversity in conceptions and implications for perceptions in the case of South Africa, three dominant modes of management exist. In industries prone towards Afrocentric and Synergistic Inspirational management styles, KM growth, and to a minor degree the management of ICT and information, was higher than in industries lenient towards the Eurocentric management style. However, this trend was not supported by the overall KM maturity score achieved. Arguably, this hint at the possibility that it is more the case of certain industries catching-up, than the case of Afrocentric and Synergistic Inspirational management styles are outperforming the Eurocentric management 
style. Of interest is that in organizations more prone towards Afrocentric and Synergistic Inspirational management styles, operational personnel's perception is higher (resources and services) or closely related (government departments) to the perception of senior management's. In contrast, in organizations more lenient towards the Eurocentric management style, score forwarded by operational personnel, is consistently lower than the scores forwarded by middle and senior management. This finding is similar and supportive of the argument proposed by Finestone and Snyman (2005) and King et al. (2007) that Afrocentric and Synergistic Inspirational managers follow a more "open door" policy regarding decision-making and the sharing of knowledge. Arguably, operational personnel in Afrocentric and Synergistic Inspirational organizations are more a part of the vesting of a KM culture and actively involved in the implementation of KM, than their counterparts in Eurocentric organizations.

\section{Future studies/implications}

The results reported here strengthen concern that the Software Engineering Institute's Capability Maturity Model is biased in measuring KM maturity. Findings indicate that there is a tendency to favour endeavours in IM, directly supported by ICT, above endeavours than require human intervention and/or a human component to succeed.

An interesting observation is the correlation between a clearly defined IM Policy and Strategy and the understanding of IM being a prerequisite for KM. Because of confusion surrounding the difference between ICT, IM and KM, full KM maturity may never be reached. A long-term development plan to address the establishment of ICT infrastructures and IM systems in support of KM, might prove to be quite valuable in the continued quest to manage knowledge successfully.

Due to the diversity of industry groupings, these findings are applicable to organizations examining the role ICT and IM play in the establishment of KM maturity. This study may therefore be viewed as a "pilot study" to provide a baseline and insight into future research of IM for enabling KM.

This baseline data can inform other empirical studies that more particularly investigate the perceived 'enablement' afforded by technology facilitated information management and knowledge creation. These further studies can also probe the significance of cultural differences precipitated by race, age, ethnicity, gender, etc. in both further defining agreement on the meaning of these terms and also exploring the implications of such insights for usage and adoption of ICT and IM for KM, including leveraging its potential for organizational innovation/advancement.

While varying conceptions of knowledge management exist amongst eastern and western theorists, this study provides valuable baseline data which can support further studies of both local and global scope and significance. Such investigations can explore varying perceptions of technology, information, and knowledge outside the scope of this study. However, this study does set the stage for investigating diversity in conceptions and implications for perceptions of management modes.

\section{Limitations}

A limitation of the study was the focus on a single country's industrial base, South African. Replicating this study in other developing as well as developed countries would be most informative. In the same light, a longitudinal study might identify trends in different industries, regions, and capital markets.

The use of a four-point Likert scale, used in the KM maturity questionnaire may not be sensitive enough. Expanding the number of possible responses might offer a more nuanced analysis of trends.

\section{Appendix A.}

Survey questions: ICT management.

\begin{tabular}{|c|c|c|c|}
\hline Question & Frequency & Percentage & $\begin{array}{l}\text { Cumulative } \\
\text { percentage }\end{array}$ \\
\hline \multicolumn{4}{|l|}{ q.5: Evaluating an ICT system } \\
\hline 1. Yes, definitely & 259 & 59.95 & 59.95 \\
\hline 2. Yes, but not significantly & 136 & 31.48 & 91.44 \\
\hline $\begin{array}{l}\text { 3. No, but probably within } \\
\text { the next } 5 \text { years }\end{array}$ & 25 & 5.79 & 97.22 \\
\hline 4. No & 12 & 2.78 & 100.00 \\
\hline \multicolumn{4}{|l|}{ q.6: Designing an ICT system } \\
\hline 1. Yes, definitely & 226 & 52.44 & 52.44 \\
\hline 2. Yes, but not significantly & 124 & 28.77 & 81.21 \\
\hline $\begin{array}{l}\text { 3. No, but probably within } \\
\text { the next } 5 \text { years }\end{array}$ & 47 & 10.90 & 92.11 \\
\hline 4. No & 34 & 7.89 & 100.00 \\
\hline \multicolumn{4}{|l|}{ q.7: Planning an ICT system } \\
\hline 1. Yes, definitely & 263 & 61.02 & 61.02 \\
\hline 2. Yes, but not significantly & 126 & 29.23 & 90.26 \\
\hline $\begin{array}{l}\text { 3. No, but probably within } \\
\text { the next } 5 \text { years }\end{array}$ & 33 & 7.66 & 97.91 \\
\hline 4. No & 9 & 2.09 & 100.00 \\
\hline \multicolumn{4}{|l|}{ q.8: Effective ICT infrastructure } \\
\hline 1. Yes, definitely & 196 & 45.27 & 45.27 \\
\hline 2. Yes, but not significantly & 162 & 37.41 & 82.68 \\
\hline $\begin{array}{l}\text { 3. No, but probably within } \\
\text { the next } 5 \text { years }\end{array}$ & 53 & 12.24 & 94.92 \\
\hline 4. No & 22 & 5.08 & 100.00 \\
\hline \multicolumn{4}{|l|}{ q.9: ICT is regarded as } \\
\hline $\begin{array}{l}\text { 1. An enabler of knowledge } \\
\text { management }\end{array}$ & 336 & 78.69 & 78.69 \\
\hline 2. Knowledge management & 91 & 21.31 & 100.00 \\
\hline
\end{tabular}

\section{Appendix B.}

Survey questions: information management.

\begin{tabular}{|c|c|c|c|}
\hline Question & Frequency & Percentage & $\begin{array}{l}\text { Cumulative } \\
\text { percentage }\end{array}$ \\
\hline \multicolumn{4}{|l|}{ q.10: Clearly defined IM policy } \\
\hline 1. Yes, definitely & 163 & 37.56 & 37.56 \\
\hline 2. Yes, but not significantly & 138 & 31.80 & 69.35 \\
\hline $\begin{array}{l}\text { 3. No, but probably within } \\
\text { the next } 5 \text { years }\end{array}$ & 92 & 21.20 & 90.55 \\
\hline 4. No & 41 & 9.45 & 100.00 \\
\hline \multicolumn{4}{|l|}{ q.11: Clearly defined IM strategy } \\
\hline 1. Yes, definitely & 158 & 36.41 & 36.41 \\
\hline 2. Yes, but not significantly & 150 & 34.56 & 70.97 \\
\hline $\begin{array}{l}\text { 3. No, but probably within } \\
\text { the next } 5 \text { years }\end{array}$ & 92 & 21.20 & 92.17 \\
\hline 4. No & 34 & 7.83 & 100.00 \\
\hline \multicolumn{4}{|c|}{ q.12: Understand which information resources are crucial to the business } \\
\hline 1. Yes, definitely & 229 & 52.76 & 52.76 \\
\hline 2. Yes, but not significantly & 157 & 36.18 & 88.94 \\
\hline $\begin{array}{l}\text { 3. No, but probably within } \\
\text { the next } 5 \text { years }\end{array}$ & 36 & 8.29 & 97.24 \\
\hline 4. No & 12 & 2.76 & 100.00 \\
\hline \multicolumn{4}{|c|}{ q.13: Is it clear which managers are accountable for information resources } \\
\hline 1. Yes, definitely & 171 & 39.40 & 39.40 \\
\hline 2. Yes, but not significantly & 177 & 40.78 & 80.18 \\
\hline $\begin{array}{l}\text { 3. No, but probably within } \\
\text { the next } 5 \text { years }\end{array}$ & 56 & 12.90 & 93.09 \\
\hline 4. No & 30 & 6.91 & 100.00 \\
\hline \multicolumn{4}{|c|}{ q.14: Key information is easily available } \\
\hline 1. Yes, definitely & 134 & 30.88 & 30.88 \\
\hline 2. Yes, but not significantly & 197 & 45.39 & 76.27 \\
\hline $\begin{array}{l}\text { 3. No, but probably within } \\
\text { the next } 5 \text { years }\end{array}$ & 72 & 16.59 & 92.86 \\
\hline 4. No & 31 & 7.14 & 100.00 \\
\hline
\end{tabular}


Appendix B (Continued)

\begin{tabular}{|c|c|c|c|}
\hline Question & Frequency & Percentage & $\begin{array}{l}\text { Cumulative } \\
\text { percentage }\end{array}$ \\
\hline \multicolumn{4}{|c|}{ q.15: Employees are trained to access sources of information } \\
\hline 1. Yes, definitely & 104 & 23.96 & 23.96 \\
\hline 2. Yes, but not significantly & 179 & 41.24 & 65.21 \\
\hline $\begin{array}{l}\text { 3. No, but probably within } \\
\text { the next } 5 \text { years }\end{array}$ & 115 & 26.50 & 91.71 \\
\hline 4. No & 36 & 8.29 & 100.00 \\
\hline \multicolumn{4}{|c|}{ q.16: Identification of information needs } \\
\hline 1. Yes, definitely & 177 & 40.78 & 40.78 \\
\hline 2. Yes, but not significantly & 175 & 40.32 & 81.11 \\
\hline $\begin{array}{l}\text { 3. No, but probably within } \\
\text { the next } 5 \text { years }\end{array}$ & 68 & 15.67 & 96.77 \\
\hline 4. No & 14 & 3.23 & 100.00 \\
\hline \multicolumn{4}{|l|}{ q.17: Acquisition of information } \\
\hline 1. Yes, definitely & 159 & 36.81 & 36.81 \\
\hline 2. Yes, but not significantly & 214 & 49.54 & 86.34 \\
\hline $\begin{array}{l}\text { 3. No, but probably within } \\
\text { the next } 5 \text { years }\end{array}$ & 47 & 10.88 & 97.22 \\
\hline 4. No & 12 & 2.78 & 100.00 \\
\hline \multicolumn{4}{|l|}{ q.18: Information storage } \\
\hline 1. Yes, definitely & 201 & 46.42 & 46.42 \\
\hline 2. Yes, but not significantly & 164 & 37.88 & 84.30 \\
\hline $\begin{array}{l}\text { 3. No, but probably within } \\
\text { the next } 5 \text { years }\end{array}$ & 62 & 14.32 & 98.61 \\
\hline 4. No & 6 & 1.39 & 100.00 \\
\hline \multicolumn{4}{|l|}{ q.19: Information distribution } \\
\hline 1. Yes, definitely & 139 & 32.03 & 32.03 \\
\hline 2. Yes, but not significantly & 201 & 46.31 & 78.34 \\
\hline $\begin{array}{l}\text { 3. No, but probably within } \\
\text { the next } 5 \text { years }\end{array}$ & 77 & 17.74 & 96.08 \\
\hline 4. No & 17 & 3.92 & 100.00 \\
\hline \multicolumn{4}{|l|}{ q.20: Information retrieval } \\
\hline 1. Yes, definitely & 152 & 35.02 & 35.02 \\
\hline 2. Yes, but not significantly & 199 & 45.85 & 80.88 \\
\hline $\begin{array}{l}\text { 3. No, but probably within } \\
\text { the next } 5 \text { years }\end{array}$ & 69 & 15.90 & 96.77 \\
\hline 4. No & 14 & 3.23 & 100.00 \\
\hline \multicolumn{4}{|l|}{ q.21: Information disposal } \\
\hline 1. Yes, definitely & 98 & 22.58 & 22.58 \\
\hline 2. Yes, but not significantly & 198 & 45.62 & 68.20 \\
\hline $\begin{array}{l}\text { 3. No, but probably within } \\
\text { the next } 5 \text { years }\end{array}$ & 104 & 23.96 & 92.17 \\
\hline 4. No & 34 & 7.83 & 100.00 \\
\hline \multicolumn{4}{|l|}{ q.22: Protection of information } \\
\hline 1. Yes, definitely & 180 & 41.47 & 41.47 \\
\hline 2. Yes, but not significantly & 158 & 36.41 & 77.88 \\
\hline $\begin{array}{l}\text { 3. No, but probably within } \\
\text { the next } 5 \text { years }\end{array}$ & 76 & 17.51 & 95.39 \\
\hline 4. No & 20 & 4.61 & 100.00 \\
\hline \multicolumn{4}{|c|}{ q.23: Determining the value and cost of information } \\
\hline 1. Yes, definitely & 101 & 23.33 & 23.33 \\
\hline 2. Yes, but not significantly & 155 & 35.80 & 59.12 \\
\hline $\begin{array}{l}\text { 3. No, but probably within } \\
\text { the next } 5 \text { years }\end{array}$ & 131 & 30.25 & 89.38 \\
\hline 4. No & 46 & 10.62 & 100.00 \\
\hline \multicolumn{4}{|c|}{ q.24: Inventory of information entities } \\
\hline 1. Yes, definitely & 137 & 31.57 & 31.57 \\
\hline 2. Yes, but not significantly & 156 & 35.94 & 67.51 \\
\hline $\begin{array}{l}\text { 3. No, but probably within } \\
\text { the next } 5 \text { years }\end{array}$ & 85 & 19.59 & 87.10 \\
\hline 4. No & 56 & 12.90 & 100.00 \\
\hline \multicolumn{4}{|c|}{ q.25: Inventory management systems } \\
\hline 1. Yes, definitely & 182 & 41.94 & 41.94 \\
\hline 2. Yes, but not significantly & 156 & 35.94 & 77.88 \\
\hline $\begin{array}{l}\text { 3. No, but probably within } \\
\text { the next } 5 \text { years }\end{array}$ & 69 & 15.90 & 93.78 \\
\hline 4. No & 27 & 6.22 & 100.00 \\
\hline \multicolumn{4}{|l|}{ q.26: Databases } \\
\hline 1. Yes, definitely & 230 & 53.00 & 53.00 \\
\hline 2. Yes, but not significantly & 140 & 32.26 & 85.25 \\
\hline
\end{tabular}

Appendix B (Continued)

\begin{tabular}{lccc}
\hline Question & Frequency & Percentage & $\begin{array}{c}\text { Cumulative } \\
\text { percentage }\end{array}$ \\
\hline $\begin{array}{l}\text { 3. No, but probably within } \\
\text { the next 5 years }\end{array}$ & 47 & 10.83 & 96.08 \\
4. No & 17 & 3.92 & 100.00 \\
$\begin{array}{l}\text { q.27: Information services/library } \\
\text { 1. Yes, definitely }\end{array}$ & 157 & 36.18 & 36.18 \\
$\begin{array}{l}\text { 2. Yes, but not significantly } \\
\text { 3. No, but probably within } \\
\text { the next 5 years }\end{array}$ & 133 & 30.65 & 66.82 \\
$\begin{array}{l}\text { 4. No } \\
\begin{array}{l}\text { q.28: Information management is regarded as } \\
\text { 1. A prerequisite for } \\
\text { knowledge management }\end{array}\end{array}$ & 296 & 24.19 & 91.01 \\
2. Knowledge management & 129 & 69.65 & 100.00 \\
\hline
\end{tabular}

\section{References}

Ariyachandra, T. R., \& Frolic, M. N. (2008). Critical success factors in business performance management-Striving for success. Information Systems Management, 25(2), 113-120.

Bain and Company. (2001). Management tools. MA: Boston.

Boon, J. A. (1990). Information management: An educational perspective. South African Journal of Library and Information Science, 58(4), 319-326.

Botha, D. F., \& Fouche, B. (2002). Knowledge management practice in the South African business sector: Preliminary findings of a longitudinal study. South African Journal of Business Management, 33(2), 13-19.

Cornford, T., \& Smithson, S. (2004). Project Research in Information Systems: A Student's Guide. London: MacMillan Press.

Crosby, Philip (1978); Quality is free: the art of making quality certain. McGrawHill Paulk, M., Curtis B., Chrissis M., Weber C. (1993) ‘Capability maturity model, Version 1. 1', IEEE Software, 10(4), 18-27.

Damodaran, L., \& Olphert, W. (2000). Barriers and facilitators to the use of knowledge management systems. Behaviour and Information Technology, 19(6), 405-413.

Finestone, N., \& Snyman, M. M. M. (2005). Corporate South Africa-making multicultural knowledge sharing work. Journal of Knowledge Management, 9(4), 128-169.

Gallagher, S., \& Hazlett, S. (2004). Using the knowledge management maturity mode as an evaluation tool [Online]. Available http://s.gallagher@qub.ac.uk. Accessed 12 August 2007.

Gurteen, D. (1998). Knowledge, creativity and Innovation. Journal of Knowledge Management, 2(1), 5-13.

Grey, D. (1998). Knowledge management and information management: The differences [Online]. Available www.smithweaversmith.com $/ \mathrm{km}$-im.htm. Accessed 26 May 2008.

Hasanali, F. (2002). The critical success factors of knowledge management [Online] Available http://www.kmadvantage.com/docs/km. Accessed 31 August 2005.

Henczel, S. (2000). The information audit as a first step towards effective knowledge management: An opportunity for the special librarian. Inspel, 34(3/4), 210-226.

Horwitz, F. M., Bowmaker-Falconer, A., \& Searll, P. (1996). Human resource development and managing diversity in South Africa. International Journal of Manpower, 17(4/5), 134-151.

Kazimi, J., Dasgupta, R. R., \& Natarajan, G. (2004). The rise, fall and rise of knowledge management [Online]. Available http://www.zenzar.com/pdfs/km2.pdf. Accessed 12 August 2007.

King, N. (2005). Elements that influence knowledge sharing, as an important prerequisite for successful knowledge management, in a multicultural environment: A South African Perspective. BCom Hons Thesis. University of Pretoria. Unpublished.

King, N., Kruger, C. J., \& Pretorius, J. (2007). Knowledge management in a multicultural environment: A South African perspective". Aslib Proceedings, 59(3), 285-299.

KPMG (1999). Knowledge Management Framework Assessment Exercise [Online]. Available http://www.kpmg.co.uk/, Accessed, 22 August 2008.

Kruger, C. J., \& Snyman, M. M. M. (2005). The formulation of a strategic knowledge management maturity model. South African Journal of Information Management 7(2.). Electronic Journal. Available http://www.sajim.co.za. Accessed 15 October 2007

Kruger, C. J., \& Snyman, M. M. M. (2007). A guideline for assessing the knowledge management maturity of organizations. South African Journal of Information Management, 9(3). Electronic Journal [Online]. Available www.sajim.co.za. Accessed 15 October 2007

Microsoft (1999); IT Advisor for Knowledge Management [Online]. Available 'http://www.microsoft.com/enterprise/building/advisor/KM' Accessed, 03 November 2008.

Parlby, D. (1999a). The Knowledge Journey, KPMG Consulting [Online]. Available http://www.kpmg.co.uk/, Accessed, 22 August 2008.

Parlby, D. (1999b). The Power of Knowledge, KPMG Consulting [Online]. Available http://www.kpmg.co.uk/, Accessed, 22 August 2008.

Prime, N. (1999). Cross-cultural management in South Africa: Problems, obstacles, and solutions to companies [Online]. Available wwww.marketingbyu.edu/ htmlpages/ccrs/proceedings99/prime.htm. Accessed 19 August 2008. 
Salojarvi, S., Furu, P., \& Sveiby, K. (2005). Knowledge management and growth in Finnish SMEs. Journal of Knowledge Management, 9(2), 103-122.

Thomas, A., \& Bendixen, M. (2000). The management implications of ethnicity in South Africa. Journal of International Business Studies, 31(3), 507-526.

Wilson, T. D. (2002). The nonsense of knowledge management. Information Research, $8(1), 144$.

Cornelius (Neels) J Kruger is a senior lecturer at the University of Pretoria, presenting primarily postgraduate courses on MBA, MEM (Masters in Engineering Management), MPM (Masters in Project Management), MIT (Masters in Information Technology), MCom, and MPhil programs. Apart from lecturing, he has more than 14 years managerial experience in the ICT sector. He participated in the formulation/revision of numerous organizations Strategic Business Plans, especially regarding ICT and knowledge as strategic resources. Dr. Kruger hold a Phd in IT and both MBA and M.IT degrees (with distinction) from the University of Pretoria. He is a member of the Association of Professional Managers of South Africa, a contributing member to the Performance Measurement Association (PMA) Cranfield School of Management-UK, and an Emerald Group Literati Club Member and Emerald author.

Roy D. Johnson is currently a Fulbright Scholar and Extraordinary Professor of Informatics at the University of Pretoria. His research focuses on Systems Analysis, Project Management and the Transfer of Knowledge. His current work involves the study of critical and reflective thinking. He is involved in organizing and promoting active learning in the classroom and has published in numerous journals. He currently serves as Association for Information Systems (AIS) VP of Education, was just elected AIS VP of Accreditation and founded the Academy of Information Systems (IAIM) which is now the special interest group of AIS for education (SIGED: IAIM). 